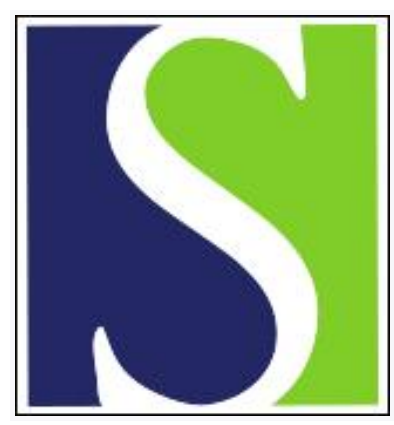

Scand J Work Environ Health 1979;5(3):297-303

https://doi.org/10.5271/sjweh.3105

Issue date: Sep 1979

Defining expected mortality in occupational studies

by Vinni K, Hakama M

Affiliation: Department of Public Health, SF-33101 Tampere 10, Finland.

Key terms: expected mortality; healthy worker effect; mortality; occupational study

This article in PubMed: www.ncbi.nlm.nih.gov/pubmed/20120579

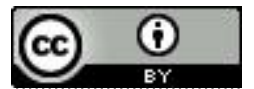




\title{
Defining expected mortality in occupational studies
}

\author{
by KARI VINNI, L.Sc., and MATTI HAKAMA, D.Sc. ${ }^{1}$
}

\begin{abstract}
VINNI, K. and HAKAMA, M. Defining expected mortality in occupational studies. Scand. j. work environ. \& health 5 (1979) 297-303. The mortality in a reference population for specific occupations was evaluated by means of occupational studies of different designs. The data originated from a random sample of 19,862 persons from among the total Finnish population. The age standardized mortality for those who had at any time belonged to the active work force in Finland was estimated to be $10 \%$ less than the average mortality for the total population. The difference was $20 \%$ if the currently active work force was compared with the total population. The standardized mortality ratio was $70 \%$ for those who had stayed for less than 10 years within the same occupational category and $80 \%$ for those with more than 10 years' work within the same occupational category. The expected mortality varied up to $50 \%$ depending on the broad occupational category and on the occupational history when compared with the total mortality in Finland.
\end{abstract}

Key words: expected mortality, healthy worker effect.

There is no standard procedure for finding referents in epidemiologic studies of occupational health $(5,8,10,11)$. Mortality within a specific occupational population is usually compared with that for the total or general population. Since selective forces affect different stages of a person's occupational history $(3,9)$, the general state of health of the total population is not comparable with that of the working population. The mortality within a specific working population is, as a rule, less than the reference mortality based on the total population, even if the occupation is subject to hazardous exposures.

1 Department of Public Health, University of Tampere, Tampere, Finland.

Reprint requests to: Mr. Kari Vinni, Department of Public Health, P.O.Box 607, SF-33101 Tampere 10, Finland.
The purpose of this study was to find a reference mortality for designs commonly used in occupational studies.

\section{MATERIAL AND METHODS}

The basic series consisted of a random sample from among the total Finnish population on 31 December 1960 drawn from the 1960 census lists of the Central Statistical Office of Finland. This sample was linked with the 1970 census. The occupations in 1960 and 1970 were recorded for the population included in the sample.

Those living on 31 December 1970 were followed from 1971 to 1975 . During this second stage, deaths in the sample were recorded by the linking of the population 
sample with the register of all death certificates issued in Finland in 1971-1975.

Persons belonging to the sample were classified by age, sex and occupation in 1960 and 1970. Occupational categories were based on Scandinavian nomenclature (13) and the following categories were used in this study:

1. Administration: those in administration, management, science and the arts, e.g., physicians, nurses, teachers, managers, clerks, typists.

2. Sales: e.g., shopkeepers, dealers, vendors, salesmen.

3. Agriculture: occupations in agriculture, forestry and fishing, e.g., farmers, forestry technicians, fishermen, lumberjacks.

4. Transportation: transportation and communications work, e.g., drivers, sailors, pilots, telegraphers, postmen.

5. Industry: including manufacturing and mining workers and laborers.

6. Services: including the police, the military, waiters, porters, janitors, domestics.

Age was classified into four groups (20$44,45-54,55-59$ and $60-64$ years). The final number of strata was $11 \times 11 \times 4 \times$ $2=968$. The observed number of deaths in 1971-1975 was estimated within each of the 968 strata. The expected number of deaths was found for the 968 strata by multiplying the person-years for each stratum by the age/sex specific mortality rates for the total sample.

The strata were combined again to provide mortality by occupational category. The follow-up from 1960 to 1970 allowed the estimation of mortality in four population groups corresponding to four different study designs:

1. No follow-up of occupation, in the active work force at some time: This category consisted of the population working either in 1960 or 1970 or in both 1960 and 1970 . The occupation for each person in the population was recorded from the information for 1970 or, if the person was not working in 1970, from the information for 1960. Those who had retired more than 10 years before 1970 were not included.
2. No follow-up occupation, currently in the active work force: This group included the population working in 1970, and the classification by occupation was based on 1970 data.

3. Follow-up of occupation, less than 10 years of exposure: The category consisted of the population not working in 1960 but working in 1970 and the population with different occupational categories in 1960 and 1970 . The classification by occupation was based on 1970 data.

4. Follow-up of occupation, more than 10 years of exposure: This population group included those working in both 1960 and 1970 within the same occupational category. Changes within the same occupational category were not considered.

\section{RESULTS}

The original sample consisted of 19,862 persons (table 1). There was a decrease of 4,185 persons from 1960 to 1970 due to deaths, emigration, and losses for follow-up. In 1970 the sample consisted of 15,677 persons who were followed from 1971 to 1975 for mortality. The total number of deaths was 875 (table 2).

The mortality among those who had been in the active work force at some time was based on the total active work force in 1960 or those entering the working population in 1960-1970. Among these 10,282 persons (table 1), 544 deaths (table 2) occurred in 1971-1975. The mortality for this population group was $10 \%$ lower than that for the total population (table 3 ). The mortality varied by occupational category and the highest standardized mortality ratio (SMR) was found for agriculture $(\mathrm{SMR}=100)$.

The mortality for the present active work force was estimated from the deaths in the population working in 1970 . The size of the working population in 1970 was 8,422 (table 1), and the number of deaths was 215 during the follow-up period (table 2 ). The mortality for the active work force 
Table 1. Random sample from the total Finnish population on 31 December 1960 by occupational status in 1960 and 1970.

\begin{tabular}{|c|c|c|c|c|c|c|c|c|c|c|}
\hline \multirow{2}{*}{$\begin{array}{l}\text { Occupational } \\
\text { category in } \\
1960\end{array}$} & \multicolumn{10}{|c|}{ Occupational category in 1970} \\
\hline & 1 & 2 & 3 & 4 & 5 & 6 & $\begin{array}{l}\text { Active } \\
\text { work } \\
\text { force }\end{array}$ & $\begin{array}{l}\text { Not } \\
\text { work- } \\
\text { ing }\end{array}$ & $\begin{array}{c}\text { Not } \\
\text { found } \\
\text { in } 1970\end{array}$ & $\begin{array}{c}\text { Total } \\
\text { sample }\end{array}$ \\
\hline 1 Administration & 747 & 43 & 13 & 10 & 38 & 18 & 869 & 198 & 272 & 1,339 \\
\hline 2 Sales & 45 & 236 & 7 & 9 & 41 & 13 & 351 & 99 & 190 & 640 \\
\hline 3 Agriculture & 34 & 19 & 1,188 & 67 & 299 & 43 & 1,650 & 885 & 612 & 3,147 \\
\hline 4 Transportation & 17 & 12 & 21 & 292 & 95 & 13 & 450 & 76 & 97 & 601 \\
\hline 5 Industry & 98 & 57 & 58 & 79 & 1,305 & 87 & 1,684 & 424 & 445 & 2,575 \\
\hline 6 Services & 33 & 14 & 16 & 12 & 30 & 260 & 371 & 178 & 262 & 811 \\
\hline Active work force & 974 & 381 & 1,303 & 469 & 1,814 & 434 & 5,375 & 1,860 & 1,878 & 9,113 \\
\hline Not working & 649 & 290 & 419 & 191 & 1,035 & 463 & 3,047 & 5,395 & 2,307 & 10,749 \\
\hline Total & 1,623 & 671 & 1,722 & 660 & 2,849 & 897 & 8,422 & 7,255 & 4,185 & 19,862 \\
\hline
\end{tabular}

Table 2. Number of deaths in the sample during the period $1971-1975$ by occupational category in 1960 and 1970 .

\begin{tabular}{|c|c|c|c|c|c|c|c|c|c|}
\hline \multirow[b]{2}{*}{$\begin{array}{l}\text { Occupational } \\
\text { category in } 1960\end{array}$} & \multicolumn{9}{|c|}{ Occupational category in 1970} \\
\hline & 1 & 2 & 3 & 4 & 5 & 6 & $\begin{array}{c}\text { Active } \\
\text { work } \\
\text { force }\end{array}$ & $\begin{array}{l}\text { Not } \\
\text { work- } \\
\text { ing }\end{array}$ & Total \\
\hline 1 Administration & 20 & 1 & 0 & 0 & 2 & 1 & 24 & 29 & 53 \\
\hline 2 Sales & 1 & 10 & 0 & 2 & $\overline{1}$ & 0 & 14 & 13 & 27 \\
\hline 3 Agriculture & 1 & 0 & 62 & 0 & 8 & 0 & 71 & 152 & 223 \\
\hline 4 Transportation & 0 & 0 & 0 & 13 & 1 & 1 & 15 & 15 & 30 \\
\hline 5 Industry & 4 & 0 & 5 & 1 & 39 & 6 & 55 & 96 & 151 \\
\hline 6 Services & 1 & 1 & 0 & 0 & 3 & 7 & 12 & 24 & 36 \\
\hline Active work force & 27 & 12 & 67 & 16 & 54 & 15 & 191 & 329 & 520 \\
\hline Not working & 7 & 2 & 5 & 1 & 4 & 5 & 24 & 331 & 355 \\
\hline Total & 34 & 14 & 72 & 17 & 58 & 20 & 215 & 660 & 875 \\
\hline
\end{tabular}

Table 3. Observed and expected number of deaths, by most recent occupational category, for those who at some time belonged to the active work force.

\begin{tabular}{lccc}
\hline $\begin{array}{l}\text { Recent occupational } \\
\text { category }\end{array}$ & Observed & Expected & $\begin{array}{c}\text { Standardized } \\
\text { mortality ratio }\end{array}$ \\
\hline Administration & 60 & 74.9 & 80 \\
Sales & 29 & 33.5 & 90 \\
Agriculture & 228 & 220.5 & 100 \\
Transportation & 31 & 33.7 & 90 \\
Industry & 155 & 173.6 & 90 \\
Services & 41 & 51.9 & 80 \\
\hline Total & 544 & 588.1 & 90 \\
\hline
\end{tabular}


in 1970 was about $20 \%$ less than that for the total population (table 4). The lowest mortality was found in industry (SMR = 70), and the highest in transportation (SMR $=100$ ).

The mortality for those with less than 10 years of exposure was based on those starting work in the 1960s (row "not working" in tables 1 and 2) and on those changing from one occupational category to another between 1960 and 1970 (the nondiagonal elements of tables 1 and 2). There were 64 deaths (table 2) among these 4,394 persons (table 1). The age-standardized mortality was $30 \%$ lower for this group than for the total population (table 5).

Table 4. Observed and expected number of deaths, by present occupational category, for the active work force.

\begin{tabular}{lccc}
\hline $\begin{array}{l}\text { Occupational category } \\
\text { in } 1970\end{array}$ & Observed & Expected & $\begin{array}{c}\text { Standardized } \\
\text { mortality ratio }\end{array}$ \\
\hline Administration & 34 & 42.4 & 80 \\
Sales & 14 & 17.9 & 80 \\
Agriculture & 72 & 82.5 & 90 \\
Transportation & 17 & 16.8 & 100 \\
Industry & 58 & 85.6 & 70 \\
Services & 20 & 22.8 & 90 \\
\hline Total & 215 & 268.0 & 80 \\
\hline
\end{tabular}

Table 5. Observed and expected number of deaths, by occupational category, for those belonging to the same occupational category for less than 10 years.

\begin{tabular}{lrrr}
\hline $\begin{array}{l}\text { Occupational category } \\
\text { in } 1970\end{array}$ & Observed & Expected & $\begin{array}{c}\text { Standardized } \\
\text { mortality ratio }\end{array}$ \\
\hline Administration & 14 & 16.8 & 80 \\
Sales & 4 & 7.9 & 50 \\
Agriculture & 10 & 11.9 & 80 \\
Transportation & 4 & 6.2 & 60 \\
Industry & 19 & 34.5 & 60 \\
Services & 13 & 11.5 & 110 \\
\hline Total & 64 & 88.8 & 70 \\
\hline
\end{tabular}

Table 6. Observed and expected number of deaths, by occupational category, for those belonging to the same occupational category for more than 10 years.

\begin{tabular}{lccc}
\hline $\begin{array}{l}\text { Occupational category } \\
\text { 1960-1970 }\end{array}$ & Observed & Expected & $\begin{array}{c}\text { Standardized } \\
\text { mortality ratio }\end{array}$ \\
\hline Administration & 20 & 25.6 & 80 \\
Sales & 10 & 10.0 & 100 \\
Agriculture & 62 & 70.6 & 90 \\
Transportation & 13 & 10.6 & 120 \\
Industry & 39 & 51.1 & 80 \\
Services & 7 & 11.3 & 80 \\
\hline Total & 151 & 179.2 & 80 \\
\hline
\end{tabular}


The mortality for those with more than 10 years of exposure was based on the population belonging to the same occupational category in 1960 and 1970 (the diagonal elements of tables 1 and 2). The size of this population group was 4,028 (table 1), and 151 (table 2) deaths occurred among the group in $1971-1975$. The overall SMR was 80 (table 6), which was slightly higher than for those with less than 10 years of exposure. Sales and transportation showed the greatest increase in mortality, while the mortality for those in the services was less than that for persons with less than 10 years in the category of services.

\section{DISCUSSION}

Differences in mortality by occupation are found from official statistics, for example, the Registrar General's Decennial Supplement in England and Wales (7) or the Norwegian statistics (12). These studies give an overall representation on the occupational mortality spectrum. If the control mortality is derived from the total population, these studies provide a biased impression of the effect of occupation on mortality because the active work force has a lower mortality than those who do not belong to the working population. The bias involved in occupational studies is commonly known as the healthy worker effect (6).

The results given by designs 1 and 2 in this study demonstrate the difference in mortality between the working population and the total population. The mortality for those who had at some time belonged to the active work force was estimated from the population who had worked at any time during the 10 years before the deaths of the period were recorded. The mortality was $10 \%$ lower for this group than for the total population. The bias was increased when only the currently active work force was considered and the estimated SMR was $\mathbf{8 0 .}$

Designs 1 and 2 recorded only the most recent occupation and were thus based on cross-sectional data of the occupational history. A standard occupational study, designed for the evaluation of the effects of specific exposures, is a follow-up study which, in addition to follow-up for deaths, also follows up data on occupations in order to evaluate the effect of the length of exposure and other related variables on mortality. Even if the study design takes into account the follow-up of the occupation, the selection for work and selection due to work conditions during the occupational history may remain uncontrolled. The biases due to these types of selection were called the "healthy population selection effect" and the "survivor population effect" by Fox and Collier (3).

Designs 3 and 4 in this study were based on a follow-up of occupation. The mortality for those with less than 10 years of exposure was $30 \%$ less than that for the total population. Those who stayed within the same occupational category for more than 10 years had a mortality rate $20 \%$ lower than that of the total population. Because the observations were based on 1960 and 1970 censuses only, the potential interruptions in the exposure between these years were not recorded.

The SMRs varied between the occupational categories. In extreme cases the bias was the opposite of that found for the total group. The differences in the mortality rates by occupational category are due to the actual occupational exposures, to other environmental risk indicators correlated with occupation, and to a bias caused by selection during the occupational history. If the control mortality refers to the total population in an occupational study, the difference between observed and expected mortality is affected by all these factors, and not only by the specific occupational exposures under study. Furthermore, it is likely that the different biases, the healthy population selection effect, and the survivor in industry effect also varied in magnitude and direction between the occupational categories.

When the effect of occupational exposures on mortality is evaluated, the referents should be comparable with the study population with respect to selective factors and to extraneous variables other than occupation. The crude occupational classification used in this study is likely to be an indicator of mortality within a social class 
rather than within a narrow working group only. The similarity of the way of life associated with the social class within the crude occupational classification and the similarities in the selective processes within related occupations imply that the broad occupational categories used in this study are likely to be a better population of reference than the total population when the expected mortality is to be found for deaths occurring in a specific occupational population. Hence the figures in tables 3 to 6 are an indication of the extent of the incomparability of the referents derived without due regard for the healthy worker selection effect and the survivor in industry effect.

However, the results in this paper are not directly applicable as estimates of expected mortality because of the designs selected. For example, the healthy worker effect is affected by the length of exposure (4). In this study only the following discrete follow-up values were used: no follow-up, less than 10 years, and more than 10 years of exposure within the same occupational category. Furthermore, the present crude occupational classification may not be optimal in evaluating the other environmental exposures associated with occupation; the reference population should be defined independently for each specific study.

For the present purposes a population of 20,000 is small enough to allow a substantial random variation in the results. So that random error would be reduced, only the total mortality was considered.

Because reference mortality is related to specific circumstances within each country, the present results are better applicable to studies carried out in Finland than elsewhere. In the 1960 s a substantial change in the population structure by industry occurred in Finland (1) with a general move from agriculture to industry. In the 1970s the changes in the industrial structure have been less substantial (2). Because the population entering industrial occupations have been young and in good general health, the mortality among those entering industry may have been lower, and among those entering agriculture higher, than for cohorts entering the active work force before or after the 1960s. Fur- thermore, the limitations in the occupational classification and in the length of follow-up make wide applicability impossible.

In spite of the limitations, the results indicate the biases involved in estimating expected mortality on the basis of the total population, and the method in itself is applicable for finding the expected mortality for occupational studies.

\section{ACKNOWLEDGMENTS}

We wish to thank the Central Statistical Office of Finland for permission to use their material.

\section{REFERENCES}

1. CENTRAL STATISTICAL OFFICE OF FINLAND. Statistical yearbook of Finland 1970. Helsinki 1971. 548 p.

2. CENTRAL STATISTICAL OFFICE OF FINLAND. Statistical yearbook of Finland 1976. Helsinki 1977. 529 p.

3. FOX, A. J. and COLLIER, P. F. Low mortality rates in industrial cohort studies due to selection for work and survival in the industry. $B r . j$. prev. soc. med. 30 (1976) $225-230$.

4. FOX, A. J. and COLLIER, P. F. Mortality experience of workers exposed to vinylchloride monomer in the manufacture of polyvinyl chloride in Great Britain. $B r . j$. ind. med. 34 (1977) 1-10.

5. GAFFEY, W. R. Critique of the standardized mortality ratio. J. occup. med. 18 (1976) $157-160$.

6. GOLDSCHMIDT, J. R. What do we expect from an occupational cohort? J. occup. med. 17 (1975) 126.

7. HER MAJESTY'S STATIONARY OFFICE. The Registrar General's decennial supplement: England and Wales (Occupational mortality tables). London 1971.

8. HERNBERG, S. Epidemiologic methods in occupational health research. Work environ. health 11 (1974) 59-68.

9. MC MICHAEL, A. J. Standardized mortality ratios and the "healthy worker effect"; Scratching beneath the surface. J. occup. med. 18 (1976) 165-168.

10. MC MICHAEL, A. J., HAYNES, S. G. and TYROLER, H. A. Observations on the 
evaluation of occupational mortality data. $J$. occup. med. 17 (1975) 128-131.

11. OHLSEN, J. and SABROE, S. Researching occupational mortality: The problem of comparison. Scand. $j$. soc. med. 7 (1979) 16.

Received for publication: 21 June 1979
12. STATISTISKA SENTRALBYRÅ. Yrke og dødelighet 1970-1973. Oslo 1976.

13. VALTIONEUVOSTON KIRJAPAINO. Pohjoismainen ammattiluokittelu (suomenkielinen laitos). Helsinki 1963. 337 p. 